\title{
$\mathrm{Fe}^{3+}$-Exchanged Titanate Nanotubes:
}

\section{A New Kind of Highly Active Heterogeneous Catalyst for Friedel-Crafts Type Benzylation}

\author{
Yunchen Du, ${ }^{1,2}$ Di Guo, ${ }^{2}$ Meiling Xiong, ${ }^{2}$ Yanwu Qi, ${ }^{2}$ Chenkui Cui, ${ }^{2}$ \\ Jun Ma, ${ }^{1}$ Xijiang Han, ${ }^{2}$ and Ping $\mathrm{Xu}^{2}$ \\ ${ }^{1}$ State Key Laboratory of Urban Water Resource and Environment, School of Municipal and Environmental Engineering, \\ Harbin Institute of Technology, Harbin 150090, China \\ ${ }^{2}$ Department of Chemistry, Harbin Institute of Technology, Harbin 150001, China
}

Correspondence should be addressed to Yunchen Du; yunchendu@hit.edu.cn and Ping Xu; pxu@hit.edu.cn

Received 6 January 2015; Accepted 20 April 2015

Academic Editor: Takuya Tsuzuki

Copyright ( 2015 Yunchen Du et al. This is an open access article distributed under the Creative Commons Attribution License, which permits unrestricted use, distribution, and reproduction in any medium, provided the original work is properly cited.

\begin{abstract}
Heterogeneous catalysis for Friedel-Crafts type benzylation has received much attention in recent years due to its characteristic of environmental benefits. In this paper, titanate nanotubes (TNTs) were employed as heterogeneous catalyst support, and a new kind of $\mathrm{Fe}^{3+}$-exchanged titanate nanotubes (Fe-TNTs) catalyst with highly dispersed ferric sites was constructed by an ion exchange technique. The obtained catalyst was systematically characterized by XRD, TEM, $\mathrm{N}_{2}$ adsorption, XPS, and UV-vis spectra. As expected, Fe-TNTs showed excellent catalytic activities in the benzylation of benzene and benzene derivatives. The recycling tests for Fe-TNTs were also carried out, where the reason for the gradually decreased activity was carefully investigated. Superior to some reported catalysts, the catalytic ability of used Fe-TNTs could be easily recovered by ion exchange again, indicating that Fe-TNTs herein were a highly active and durable heterogeneous catalyst for Friedel-Crafts type benzylation. These results might be helpful for the design and preparation of novel heterogeneous catalysts by combining the structural advantages of titanate nanotubes and active metal ions.
\end{abstract}

\section{Introduction}

Friedel-Crafts type benzylation, typically reacted between aromatic compounds and benzyl chloride/alcohol, is a classical chemical reaction for the production of diphenylmethane and substituted diphenylmethanes, which can be widely used in the fields of pharmaceuticals, agrochemicals, fine and bulk chemicals, and dielectric oil formulations $[1,2]$. Although some Lewis acid (e.g., $\mathrm{AlCl}_{3}, \mathrm{FeCl}_{3}$, and $\mathrm{BF}_{3}$ ) and protonic acid (e.g., $\mathrm{H}_{2} \mathrm{SO}_{4}, \mathrm{HF}$, and $\mathrm{HNO}_{3}$ ) catalysts are very active in these reactions, several undesirable problems derived from these homogeneous catalysts, including difficulty in separation and recovery, disposal of spent catalyst, corrosion, and high toxicity, severely limit their practical applications [3].

Following the advanced development of green chemistry, various kinds of heterogeneous solid catalysts, for example, zeolites, metal oxides, sulfated zirconia, clay, doped mesoporous silica, and heteropoly acids, for Friedel-Crafts type benzylation have been extensively studied in past decades [4-15]. Among those different active sites in heterogeneous catalysts, Fe-containing sites have received more and more attention due to their superior catalytic activities and low cost. For example, Choudhary and Jana investigated the activities of Fe-, Zn-, Ga-, and In-modified ZSM-5 zeolite catalysts, and they found Fe-modified ZSM-5 showed the best performance in benzylation of benzene [16]; SalavatiNiasari et al. supported $\mathrm{FeCl}_{3}, \mathrm{MnCl}_{2}, \mathrm{CoCl}_{2}, \mathrm{NiCl}_{2}, \mathrm{CuCl}_{2}$, and $\mathrm{ZnCl}_{2}$ on alumina, where $\mathrm{FeCl}_{3} / \mathrm{Al}_{2} \mathrm{O}_{3}$ exhibited much better conversion and selectivity than other catalysts in the benzylation of benzene [17]. It is well known that, besides the species of active sites, surface area and dispersion of active sites are also critical factors for the catalytic activities. Therefore, it may be an effective method to further improve 
catalytic activity in benzylation by dispersing Fe-containing sites on some supports with high surface area.

In recent years, mesoporous silica materials emerged as ideal catalyst supports because of their high surface area, which have been considered to be favorable for the dispersion of Fe-containing sites [2, 9, 11, 18-26]. As expected, these $\mathrm{Fe}$-containing mesoporous silica materials are very active for Friedel-Crafts type benzylation. Vinu et al. developed a method for the direct synthesis of Fe-containing SBA-15 that was rich in tetrahedrally coordinated $\mathrm{Fe}^{3+}$ ions under weak acidic condition $(\mathrm{pH} \approx 2.2)$, and the obtained catalysts showed superior catalytic performance and recyclability as compared to the Al-SBA-15 catalysts in the benzylation of benzene [18]; Sun et al. and Lei et al. loaded small $\mathrm{Fe}_{2} \mathrm{O}_{3}$ nanoparticles into SBA-15 with the assistance of surfactants and chemical vapor infiltration, respectively, and these $\mathrm{Fe}_{2} \mathrm{O}_{3} / \mathrm{SBA}-15$ catalysts could trigger the reaction between benzene and benzyl chloride even at relatively low temperature $\left(60^{\circ} \mathrm{C}\right)[19,20]$; Li et al. reported a simple incipient wetness coimpregnation route to produce highly dispersed $\mathrm{Fe}$ (III) centers in SBA-15 by casting furfuryl alcohol solution of iron acetylacetonate, and the catalysts displayed extraordinarily high catalytic performance with a $100 \%$ yield of monoalkylated product even in $1.5 \mathrm{~min}$ at $60^{\circ} \mathrm{C} \mathrm{[2];}$ our group also fabricated a series of novel Fe-containing mesoporous materials (Fe-JLU-15s) by using semifluorinated surfactant as template, which were generally active for the benzylation of various aromatic compounds [11]. Although the significant enhancement has been achieved in these $\mathrm{Fe}$-containing mesoporous silica materials, it is not easy to maintain their catalytic activities during the processes of recycling and regeneration, since amorphous nature of mesoporous silica will result in the collapse of structure and leaching of active sites [2, 20-22]. Therefore, it still remains a challenge to find new supports that can possess stable structure and anchor Fe-containing active sites.

Since the discovery of multilayered titanate nanotubes (TNTs) [27], they have shown promising applications in photocatalysis, catalyst support, batteries, absorption, gas sensing, and hydrogen storage due to their high surface area, large pore volume, stable one-dimensional nanostructures, wideband gap semiconductor properties, and excellent ion exchange ability [28-33]. More recently, Hara et al. studied the acidity of protonated TNTs in detail, and they found that protonated TNTs could be also used as an active heterogeneous catalyst for benzylation of toluene, and the high protonation degree was favorable for the high yield of benzyl toluene $[34,35]$. However, due to the absence of better effective sites, the benzylation of benzene, which is more difficult to be catalyzed, has not been mentioned. By considering unique characteristics of TNTs and superior catalytic activities of $\mathrm{Fe}$-containing species, the performance of $\mathrm{Fe}^{3+}$-exchanged TNTs in Friedel-Crafts type benzylation can be expected. On one hand, multilayered crystalline structure of TNTs is more stable than amorphous structure of mesoporous silica materials. On the other hand, ion exchange ability of TNTs can produce high dispersion of $\mathrm{Fe}$-containing active sites, even to extent of single active site. Moreover, electrostatic interaction between titanates and $\mathrm{Fe}^{3+}$ may suppress the leaching of Fe-containing active sites. Herein, we investigated the catalytic behaviors of $\mathrm{Fe}^{3+}$-exchanged TNTs as a new heterogeneous catalyst for the Friedel-Crafts type benzylation.

\section{Materials and Methods}

2.1. Sample Preparation. Titanate nanotubes (TNTs) were prepared by hydrothermal method according to a previous literature [27]. Briefly, $3.0 \mathrm{~g}$ of anatase $\mathrm{TiO}_{2}$ powder was dispersed into $100 \mathrm{~mL}$ of $\mathrm{NaOH}$ aqueous solution $(10 \mathrm{M})$ under magnetic stirring for $30 \mathrm{~min}$. After that, the mixture was transferred into a Teflon-lined stainless-steel autoclave and sealed to heat at $140^{\circ} \mathrm{C}$ for $16 \mathrm{~h}$. The white powder deposited at the bottom of Teflon liner was redispersed into $0.1 \mathrm{M} \mathrm{HCl}$ solution to neutralize the residual $\mathrm{NaOH}$. Then, the white powder was collected by filtration, thoroughly washed with distilled water until the $\mathrm{pH}$ value of the filtrate reached 7.0, and dried at $60^{\circ} \mathrm{C}$ to obtain titanate nanotubes (TNTs).

To obtain $\mathrm{Fe}^{3+}$-exchanged TNTs, $1.0 \mathrm{~g}$ of protonated TNTs was dispersed into $50 \mathrm{~mL}$ of $\mathrm{FeCl}_{3}$ solution $(0.25 \mathrm{M})$ and stirred for $24 \mathrm{~h}$. $\mathrm{Fe}^{3+}$-exchanged TNTs were collected by centrifugation and washed with distilled water. This process should be repeated many times until $\mathrm{Cl}^{-}$in solution could not be detected by $\mathrm{AgNO}_{3}$ solution (1M). Finally, the yellow powder was dried at $80^{\circ} \mathrm{C}$ and denoted as Fe-TNTs.

2.2. Characterization. Powder X-ray diffraction (XRD) data were recorded on a Rigaku D/MAXRCX-ray diffractometer with $\mathrm{CuK} \alpha$ radiation source $(45.0 \mathrm{kV}, 50.0 \mathrm{~mA})$. Transmission electron micrograph (TEM) images were obtained on a Tecnai $\mathrm{G}^{2} \mathrm{~F} 30$ operating at an accelerating voltage of $200 \mathrm{kV}$. $\mathrm{X}$-ray photoelectron spectroscopy (XPS) was recorded at room temperature in a PHI 5700 ESCA system with $\mathrm{Al} \mathrm{K} \alpha$ radiation $(1486.6 \mathrm{eV})$. The diffuse reflectance $\mathrm{UV}$-vis spectra for powder samples were obtained on a spectrometer PerkinElmer Lambda $750 \mathrm{UV}$-vis spectrometer equipped with an integrating sphere, and $\mathrm{BaSO}_{4}$ was used as an internal standard. Nitrogen adsorption isotherms were obtained at $-196^{\circ} \mathrm{C}$ on a QUADRASORB SI-KR/MP. Samples were normally prepared for measurement by degassing at $120^{\circ} \mathrm{C}$ until a final pressure of $1 \times 10^{-3}$ Torr was reached. Pore size distributions were calculated using Barrett-Joyner-Halenda (BJH) method.

2.3. Catalytic Tests. The liquid phase benzylation of benzene with benzyl chloride (BC) was carried out in a $50 \mathrm{~mL}$ three-necked round-bottomed flask equipped with a reflux condenser and heated in a precisely controlled oil bath under atmospheric pressure. In a typical run, $100 \mathrm{mg}$ of catalyst, $10 \mathrm{~mL}$ of benzene, and $2 \mathrm{mmol}$ of dodecane (internal standard) were added into the flask, followed by stirring for $30 \mathrm{~min}$ at required temperature $\left(60 \sim 80^{\circ} \mathrm{C}\right)$. Then, $0.5 \mathrm{~mL}$ of BC was finally added. The products were analyzed by gas chromatography (Varian CP-3800) with a FID detector. The benzylations of other aromatic compounds were carried out at $70^{\circ} \mathrm{C}$, and their experimental procedures were the same as benzene except that equivalent mole of aromatic compounds was used. 


\section{Results and Discussion}

Figure 1 shows the XRD patterns of TNTs and Fe-TNTs. It is clear that TNTs exhibit four well-resolved diffraction peaks at $\sim 9.6^{\circ}, 24.4^{\circ}, 28.6^{\circ}$, and $48.5^{\circ}$, which can be indexed as the (200), (110), (211), and (020) planes of crystalline phase of $\mathrm{Na}_{x} \mathrm{H}_{2-x} \mathrm{Ti}_{3} \mathrm{O}_{7}[28,36,37]$, where $\mathrm{Na}^{+}$and $\mathrm{H}^{+}$are located in interlaminations of zigzag ribbons of edge-sharing $\left[\mathrm{TiO}_{6}\right]^{2-}$ octahedrons to keep the charge balance. The (200) diffraction peak at $\sim 9.6^{\circ}$ is characteristic of the layered structure of TNTs, and the $d$ value (ca. 9.2 $\AA$ ) corresponds to the spacing between the neighboring $\left[\mathrm{TiO}_{6}\right]^{2-}$ octahedron layers in the walls of TNTs $[38,39]$. There are no diffraction peaks assigned to anatase $\mathrm{TiO}_{2}$, indicating that anatase $\mathrm{TiO}_{2}$ particles as raw materials have been completely transformed into TNTs. It has been reported that ion exchange would bring the change in the profile of XRD pattern, mainly symbolized by the weakened intensity of (200) and (211) diffraction peaks and even $\mathrm{H}^{+}$was used to replace the remaining $\mathrm{Na}^{+}$ [40-45]. Although some possible reasons such as variable chemical environment, different scattering factors, and lower crystallinity have been proposed [41-43], no scientific and reliable explanations can be widely accepted, and the only consensus is that the variations will not cause the destruction and the collapse of TNTs. Compared with the XRD pattern of TNTs, Fe-TNTs herein also present obvious variations in the intensity of (200) and (211) diffraction peaks, but the peaks at $\sim 24.4^{\circ}(110)$ and $48.5^{\circ}(020)$ are still distinguishable, which is a hint that the basic structure of TNTs is well retained.

Figure 2 shows optical and TEM images of TNTs and FeTNTs. It is very interesting that the colors of TNTs and FeTNTs powder are quite different (Figure 2, inset), where the former is white and the latter becomes yellow due to the successful introduction of Fe species. Although the chemical composition changes, Fe-TNTs still exhibit typically tubular microstructure with similar size to pristine TNTs (Figure 2), convincingly validating the fact that the structure has not been destroyed during the process of ion exchange. A closer look (Figure 2(b), inset) reveals that the external surface of Fe-TNTs is very clean without any additional deposited particles or amorphous coatings, implying that Fe species in Fe-TNTs are highly dispersed.

The structural parameters of TNTs and Fe-TNTs are determined by typical isotherms of nitrogen adsorption and desorption conducted at $77 \mathrm{~K}$. As shown in Figure 3, TNTs give standard IV-type isotherms with a sharp capillary condensation step at relative pressure $\left(P / P_{0}\right)$ from 0.4 to 1.0 , indicating a high density of mesopores in the material according to the IUPAC classification. A relatively narrow pore size distribution centered at $4.82 \mathrm{~nm}$ can be also observed, and this value is very close to that of inner diameter measured from TEM image (Figure 2). It is very important that the sample of Fe-TNTs exhibits very similar isotherms and pore size distribution, which again verifies the good maintenance of microstructure. However, one can also discover that the process of ion exchange produces a slight decrease in BET surface and total pore volume. BET surface and total pore volume of TNTs are $255 \mathrm{~m}^{2} / \mathrm{g}$ and $0.63 \mathrm{~cm}^{3} / \mathrm{g}$, respectively, while they are $224 \mathrm{~m}^{2} / \mathrm{g}$ and $0.61 \mathrm{~cm}^{3} / \mathrm{g}$ for Fe-TNTs. This

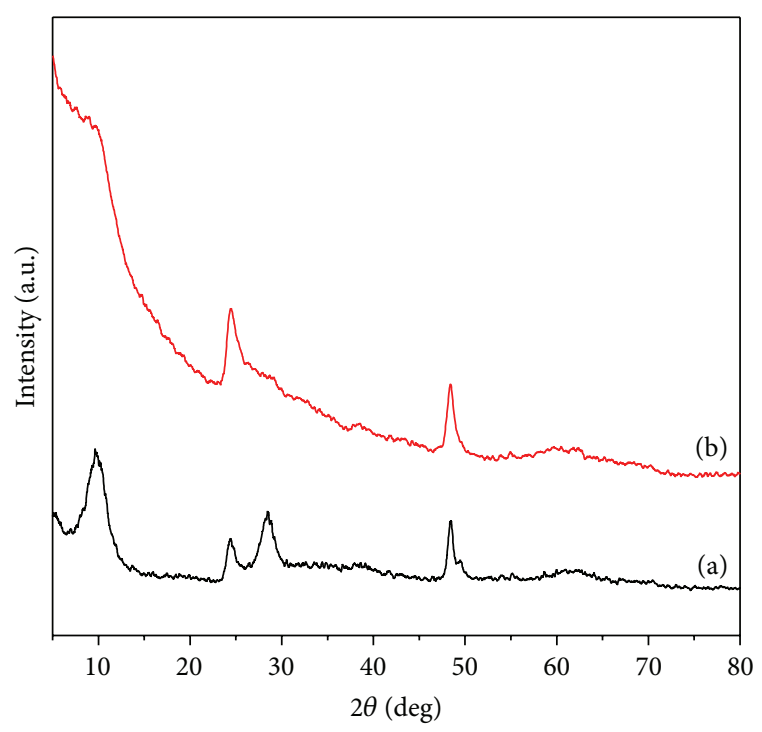

FIGURE 1: XRD patterns of pristine TNTs (a) and Fe-TNTs (b).

difference may come from the fact that element Fe has much heavier atomic weight than the substituted $\mathrm{H}$ and $\mathrm{Na}$.

XPS and UV-vis spectra are utilized to discern the existing state of Fe species in Fe-TNTs (Figures 4 and 5). In the survey of XPS spectrum for Fe-TNTs (Figure 4), the initial Auger peak of $\mathrm{Na}^{+}$at about $500 \mathrm{eV}$ disappears, and a distinguishable signal in the range of $700 \sim 730 \mathrm{eV}$ assigned to $\mathrm{Fe}$ species can be observed. This result implies that ion exchange is carried out effectively, and almost all $\mathrm{Na}^{+}$ions have been substituted. The Fe 2p spectrum of Fe-TNTs (Figure 4, inset) gives two typical peaks at 710.7 and $724.5 \mathrm{eV}$, as well as a satellite peak at $717.0 \mathrm{eV}$, which are labeled as the characteristic of ferric species [46], indicating that there is no redox reaction that occurred in the process of ion exchange. Considering the preparative system of Fe-TNTs, $\mathrm{Fe}^{3+}$ in final product can combine with $\left[\mathrm{TiO}_{6}\right]^{2-}$ octahedron, $\mathrm{OH}^{-}$, and $\mathrm{Cl}^{-}$by electrostatic interaction, whereas $\mathrm{Cl}^{-}$is easily excluded due to the absence of typical XPS peaks (Figure 4); thus $\left[\mathrm{TiO}_{6}\right]^{2-}$ octahedron and $\mathrm{OH}^{-}$may be responsible for the charge balance of Fe-TNTs. It is worth noting that the molar ratio of $\mathrm{Fe} / \mathrm{Ti}$ deduced by the survey spectrum (Figure 4 ) is about 0.198 , less than the theoretical value of ferric titanates [0.222, $\left.\mathrm{Fe}_{2}\left(\mathrm{Ti}_{3} \mathrm{O}_{7}\right)_{3}\right]$ from complete ion exchange. The inferior Fe/Ti molar ratio conceals two clues: (1) a few exchangeable sites in titanates are still not accessible for $\mathrm{Fe}^{3+}$, although the concentration of $\mathrm{Fe}^{3+}$ is much excessive; (2) the contribution of charge balance from $\mathrm{OH}^{-}$is limited, because once considerable $\mathrm{OH}^{-}$groups are involved in the final product, for example, $\mathrm{Fe}(\mathrm{OH}) \mathrm{Ti}_{3} \mathrm{O}_{7}$ or $\mathrm{Fe}(\mathrm{OH})_{2}\left(\mathrm{Ti}_{3} \mathrm{O}_{7}\right)_{1 / 2}$, the $\mathrm{Fe} / \mathrm{Ti}$ ratio will be markedly increased. That is to say, most $\mathrm{Fe}^{3+}$ ions in final product are mainly located at $\left[\mathrm{TiO}_{6}\right]^{2-}$ octahedron layers rather than other anions, and this complexation makes it difficult for $\mathrm{Fe}^{3+}$ ions to escape and aggregate and favors the formation of highly dispersed ferric sites. This assumption can be substantially supported by UV-vis spectra (Figure 5). According to previous literatures, highly dispersed ferric 


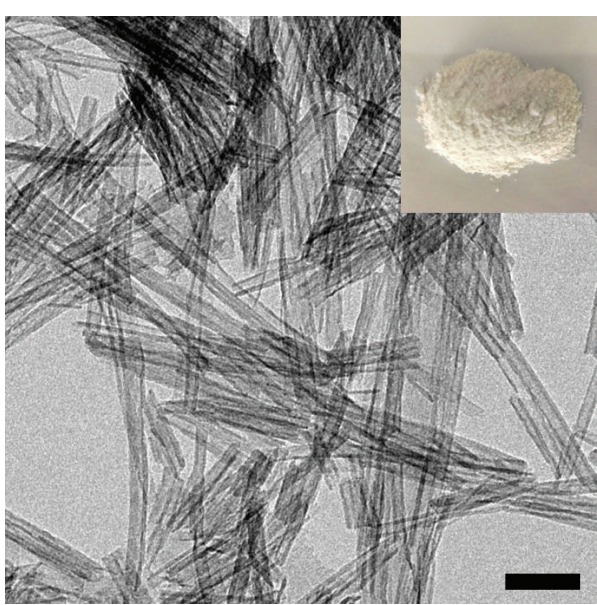

(a)

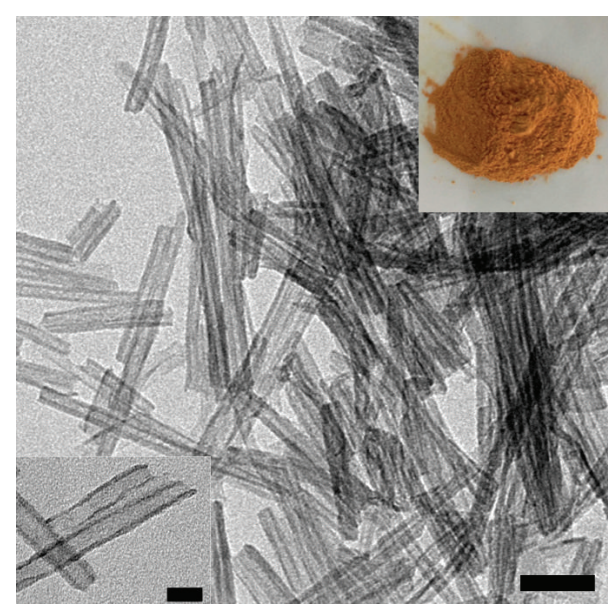

(b)

Figure 2: TEM and optical images of pristine TNTs (a) and Fe-TNTs (b). Inset is the TEM image with larger magnification of Fe-TNTs. The scale bars for (a) and (b) are $50 \mathrm{~nm}$ and $10 \mathrm{~nm}$ for the inset of (b).

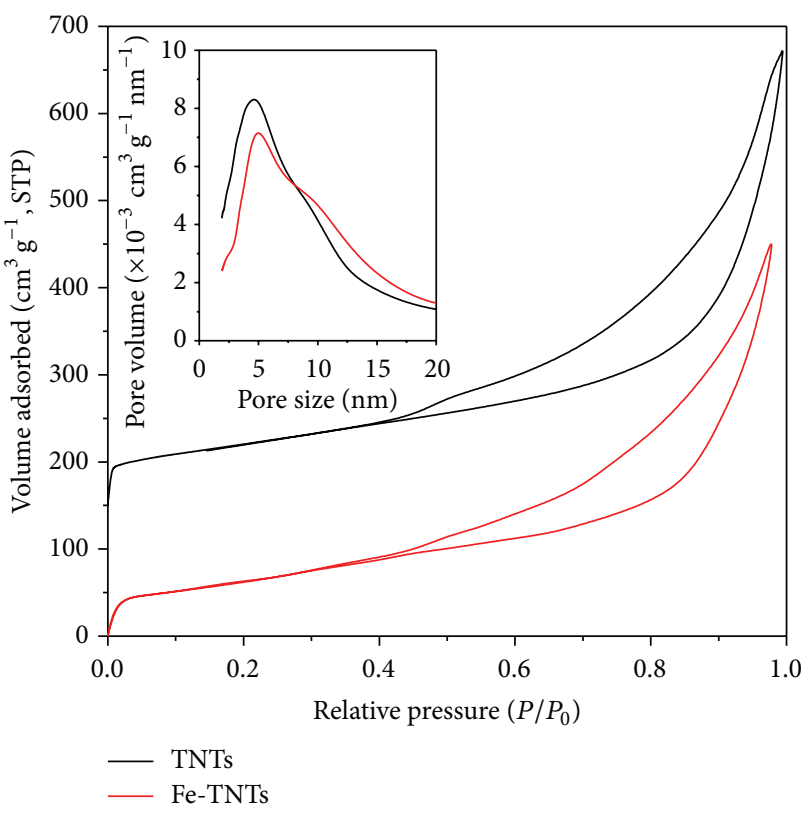

FIGURE 3: $\mathrm{N}_{2}$ adsorption/desorption isotherms and pore size distribution (inset) of TNTs and Fe-TNTs. Isotherm of TNTs has been offset $150 \mathrm{~cm}^{3} \mathrm{~g}^{-1}$ along the vertical axis for clarity.

species can produce a band in the range of $250-280 \mathrm{~nm}$ due to $\mathrm{d} \pi$-p $\pi$ charge transfer between $\mathrm{Fe}$ and $\mathrm{O}$ atoms in $\left[\mathrm{FeO}_{4}\right]^{-}$ tetrahedral geometry [47], while there will be a redshift if these dispersed ferric species aggregate to nanoclusters (e.g., $\mathrm{Fe}^{3+}$ in $\mathrm{O}_{\mathrm{h}}$ coordination between 300 and $400 \mathrm{~nm}$ ) or bulk iron oxides $(>450 \mathrm{~nm})$ [19]. Fe-TNTs herein display relative broadband centered at $270 \mathrm{~nm}$; although this band is overlapped with that of pristine TNTs, the absence of obvious absorption band in the range of 400-800 nm, especially at 350 and $550 \mathrm{~nm}$, indicates that Fe-TNTs possess highly dispersed ferric species. Similar phenomena have also been reported in some Fe-doped mesoporous materials [11, 18, 19, 21, 47].

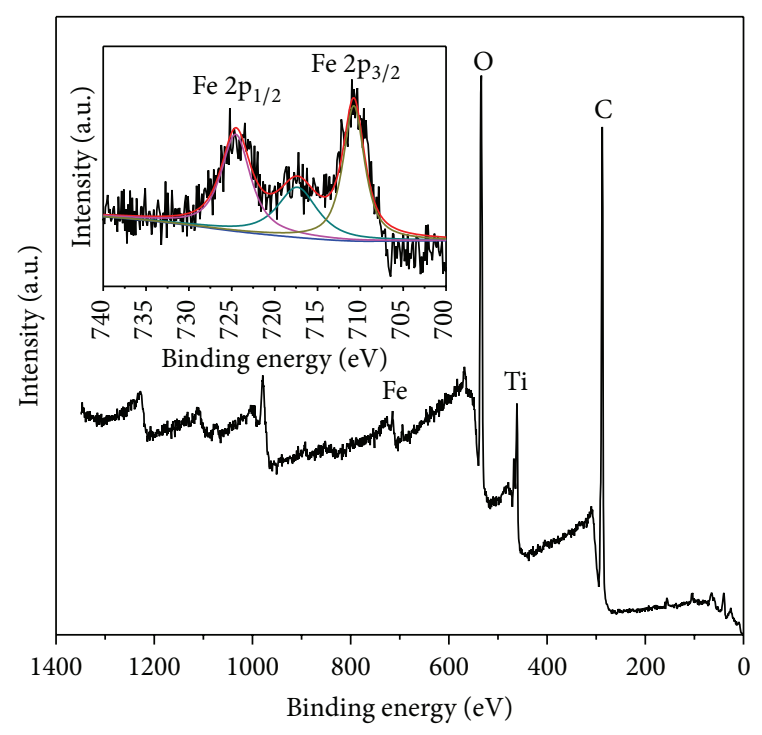

FIGURE 4: Survey of XPS spectrum of Fe-TNTs (inset is the spectrum for Fe 2p).

Figure 6 shows the conversion of $\mathrm{BC}$ and the catalytic selectivity of diphenylmethane (DPM) over Fe-TNTs at different temperature. In the studied temperature interval, $\mathrm{Fe}$ TNTs are highly effective in catalyzing the benzylation of benzene with BC, while pristine TNTs are absolutely inactive for this reaction under the same conditions, indicating that ferrite species are the primary active sites. It is worth noting that the conversion of $\mathrm{BC}$ is strongly dependent on the reaction temperature (Figure 6(a)). For example, it takes less than 10 min to reach complete $\mathrm{BC}$ conversion at $80^{\circ} \mathrm{C}$, while it will cost about $30 \mathrm{~min}$ if the reaction temperature is $70^{\circ} \mathrm{C}$. The lowered temperature not only results in the slow reaction rate but also produces obvious induction period, so that $\mathrm{Fe}$ TNTs cannot provide any detectable BC conversion until the reaction is carried out over $5 \mathrm{~min}, 10 \mathrm{~min}, 20 \mathrm{~min}$, and 


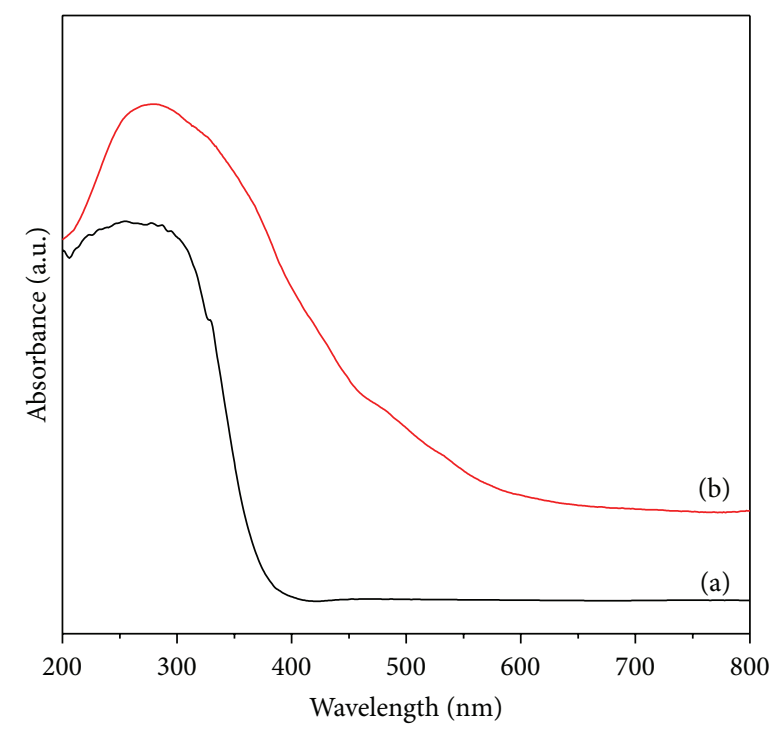

FIgURE 5: UV-vis spectra of pristine TNTs (a) and Fe-TNTs (b).

$25 \mathrm{~min}$ for $75^{\circ} \mathrm{C}, 70^{\circ} \mathrm{C}, 65^{\circ} \mathrm{C}$, and $60^{\circ} \mathrm{C}$, respectively. The phenomenon of induction period, which commonly exists in the heterogeneous catalysis of benzylation of benzene $[7,17,21$, $22,48-51]$, has been attributed to the moisture adsorbed on the catalytic sites that could delay the diffusion and activation of reaction substrates $[16,52]$. Ferric sites in Fe-TNTs are highly dispersed; thus it is not difficult to understand that these active sites are occupied by some moisture due to the hydrophilicity of $\mathrm{Fe}^{3+}$ ions. To evaluate the catalytic ability of Fe-TNTs, we also examined the conversion of BC over different heterogeneous catalysts, including Fe-containing mesoporous silica (Fe-JLU-15), Fe-containing zeolites (FeZSM-5), and sulfated zirconia, which are prepared according to previous literatures $[11,16,53]$. As shown in Figure S1 (see Figure S1 in Supplementary Material available online at http://dx.doi.org/10.1155/2015/738089) all of these heterogeneous catalysts are effective for the benzylation of benzene, while the induction periods and conversion of $\mathrm{BC}$ over sulfated zirconia are obviously inferior to those over $\mathrm{Fe}$ containing catalysts, confirming the advantages of ferric species in Friedel-Crafts type benzylation. Compared with Fe-JLU-15 and Fe-ZSM-5, the induction period of Fe-TNTs is moderate, but it can also guarantee the rapid conversion once the reaction is induced, and the conversion of $\mathrm{BC}$ over Fe-TNTs is even a little superior to that over Fe-ZSM-5, which indicates that Fe-TNTs can be taken as a novel heterogeneous catalyst with excellent catalytic activity. In addition, it can be found that the reaction temperature also impacts the selectivity of DMP (Figure 6(b)). Although BC can be consumed in a short time at relatively high temperature (e.g., $80^{\circ} \mathrm{C}$ ), the selectivity for the desired product (DPM) is very poor $(87.8 \%)$, and a large number of by-products, dibenzylbenzene (DBB), can be detected. With decreased temperature, the selectivity of DMP is effectively improved, and regular selectivity above $98 \%$ can be performed at $70^{\circ} \mathrm{C}$.

To test the generality of Fe-TNTs, some aromatic compounds with electron-donating groups, such as toluene,

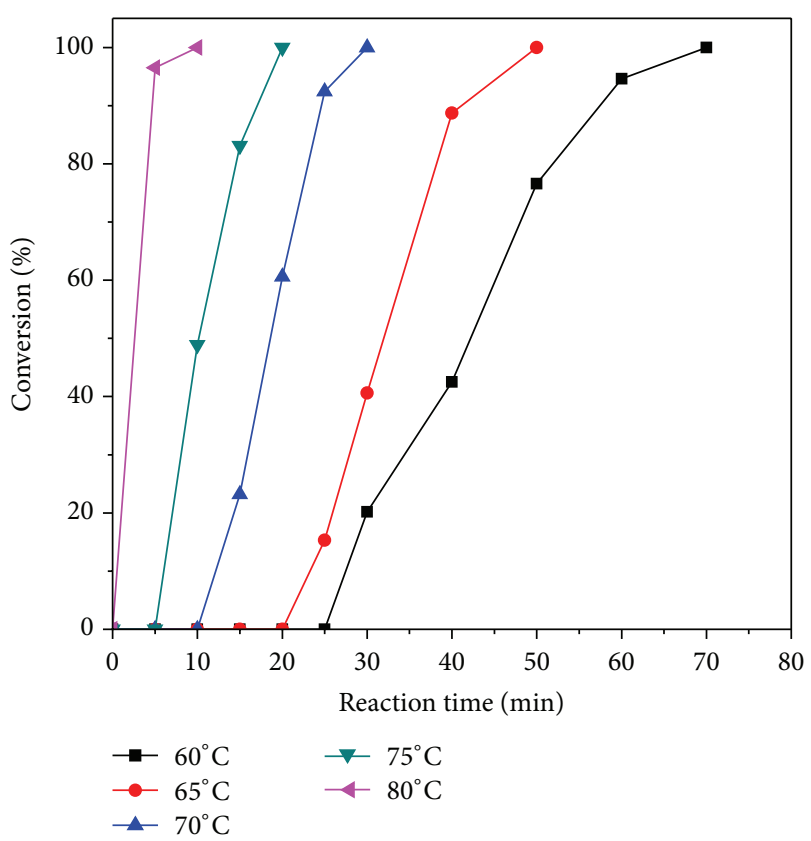

(a)

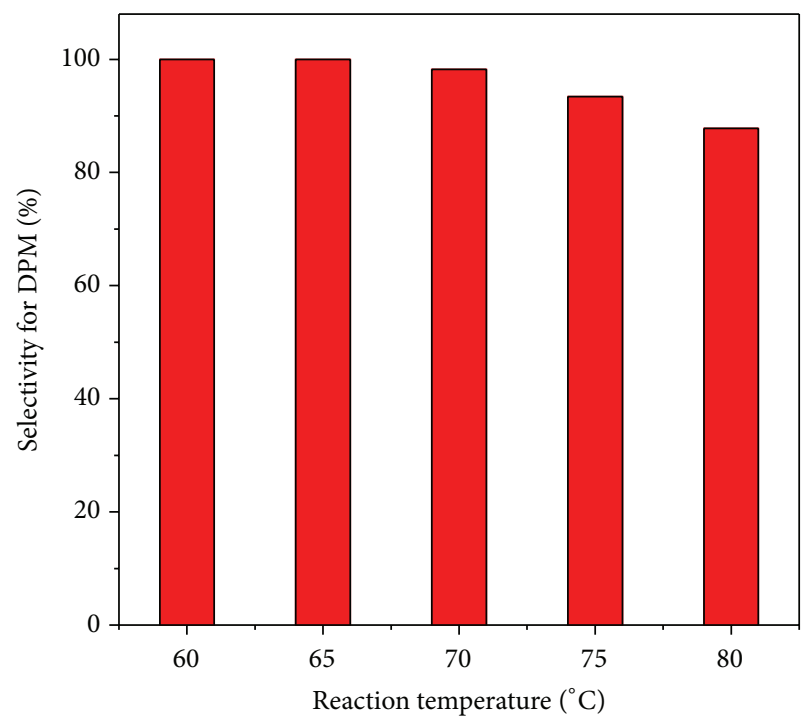

(b)

FIGURE 6: Dependence of benzyl chloride conversion on reaction time (a) and the selectivity for DPM (b) over Fe-TNTs at different reaction temperatures.

xylene, ethylbenzene, and anisole, are used to replace benzene. Based on classical mechanism of Friedel-Crafts alkylations, one or more electron-donating groups in the aromatic ring will facilitate benzylation of an aromatic compound [16]. Unfortunately, as observed in some reported heterogeneous catalysts, $\mathrm{BC}$ conversions were unexpectedly reduced by the introduction of electron-donating groups in the aromatic compounds, where the influences of steric effect and possible poisonous adsorption of aromatic substrates have been assigned to the primary reasons $[18,23,26,54]$. Table 1 presents the conversion of $\mathrm{BC}$ and product selectivity in 
TABLE 1: Benzylations of substituted benzene with benzyl chloride over Fe-TNTs at $70^{\circ} \mathrm{C}^{\mathrm{a}}$.

\begin{tabular}{lcccc}
\hline \multirow{2}{*}{ Run } & Aromatic compound & Time $^{\mathrm{b}}(\mathrm{min})$ & \multicolumn{2}{c}{ Selectivity (\%) } \\
& & & $0^{-}$ & $p^{-}$ \\
\hline 1 & Benzene & 30 & - & $100^{\mathrm{c}}$ \\
2 & Toluene & 15 & $39.2^{\mathrm{d}}$ & $60.8^{\mathrm{d}}$ \\
3 & $p$-Xylene & 12 & $100^{\mathrm{e}}$ & - \\
4 & $o$-Xylene & 9 & $100^{\mathrm{f}}$ & - \\
5 & Ethylbenzene & 15 & $24.8^{\mathrm{g}}$ & $75.2^{\mathrm{g}}$ \\
6 & Mesitylene & 6 & $100^{\mathrm{h}}$ & - \\
7 & Anisole & 24 & $33.7^{\mathrm{i}}$ & $66.3^{\mathrm{f}}$ \\
\hline
\end{tabular}

${ }^{a}$ Reaction conditions: $10 \mathrm{~mL}$ of benzene (or equivalent mole of substituted benzene), $0.5 \mathrm{~mL}$ of benzyl chloride, and $100 \mathrm{mg}$ of catalyst. The conversion was calculated from benzyl chloride.

${ }^{\mathrm{b}}$ Time required for complete conversion of benzyl chloride.

${ }^{\mathrm{c}}$ Diphenylmethane.

d $(o-)$ 2-Methyl diphenylmethane, ( $p$-) 4-methyl diphenylmethane.

e 2,5-Dimethyl diphenylmethane.

$\mathrm{f}_{2,3}$-Dimethyl diphenylmethane.

${ }^{\mathrm{g}}(o-)$ 2-Ethyl diphenylmethane, $(p-)$ 4-ethyl diphenylmethane.

${ }^{h}$ 2,4,6-Trimethyl diphenylmethane.

${ }^{i}(o-)$ 2-Methoxy diphenylmethane, ( $p$-) 4-methoxy diphenylmethane.

benzylation of aromatic compounds with various electrondonating groups over Fe-TNTs at $70^{\circ} \mathrm{C}$. It is satisfying that electron-donating groups in the aromatic ring significantly facilitate benzylation in current system, and all reactions can be carried out in accelerating models under the catalysis of Fe-TNTs, giving complete conversion of BC in less than $25 \mathrm{~min}$. However, this facilitation is not consistent with the electron-donating ability very well. For example, both $p$ xylene and $o$-xylene have two methyl groups, while they need different time for complete $\mathrm{BC}$ conversion; ethylbenzene gives the same complete conversion time with toluene, although electron-donating ability from ethyl is a little stronger than methyl in toluene. Apparently, steric effects may be another factor that should be considered in the benzylations of aromatic compounds [11]. In addition, although previous work confirmed the catalytic activities of pristine TNTs in the benzylation of toluene $[34,35]$, it is still catalytically inactive for these benzylations of substituted benzene even if we prolong the reaction to $5 \mathrm{~h}$, which can be attributed to the low protonation degree in our case. This result further demonstrates the importance of ferric species for Fe-TNTs.

The most important advantage of heterogeneous catalysts is the possibility of their regeneration and reusability. In our case, the used Fe-TNTs are regenerated by simple washing with absolute ethanol to remove the adsorbed organic species, and their catalytic activities are studied in the benzylation of benzene under the same conditions (Figure 7). As observed, the regenerated $\mathrm{Fe}$-TNTs give a quite similar activity to the fresh catalyst in their first recycling, implying the feasibility of Fe-TNTs as a reusable heterogeneous catalyst. However, the catalytic activity starts to decline when Fe-TNTs are regenerated again, represented not only by the slowing reaction rate, but also by the prolonging induction period. The situation will become worse if more recycles are applied.

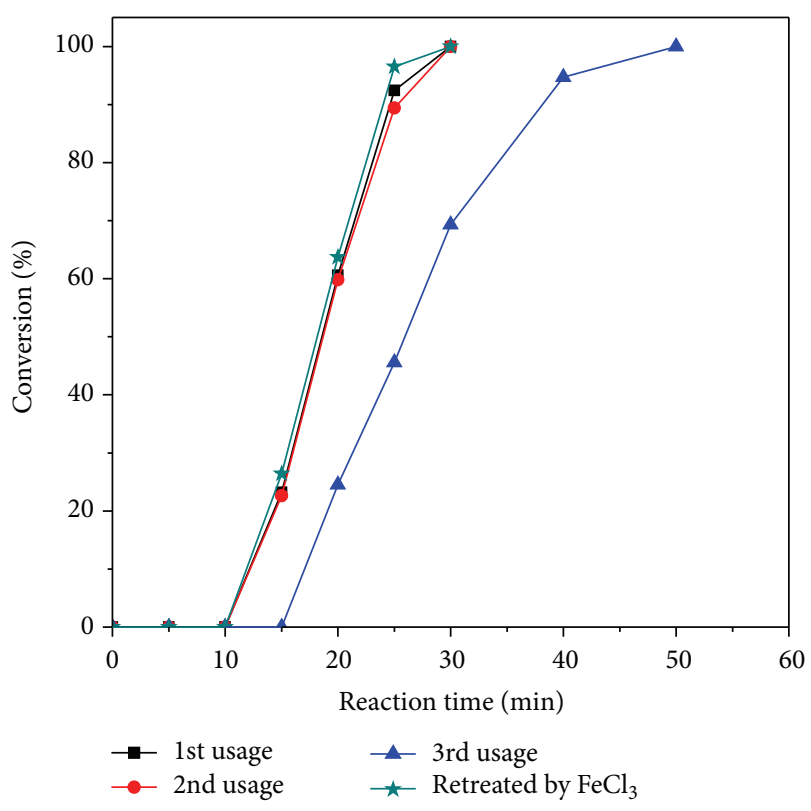

FIGURE 7: Dependence of benzyl chloride conversion on reaction time over recycled and retreated Fe-TNTs.

Driven by this phenomenon, we recharacterize the catalyst of Fe-TNTs used for three times. As shown in Figures S2-S6, the results of XRD, TEM, $\mathrm{N}_{2}$ adsorption, and UV-vis spectra are almost identical to those of fresh Fe-TNTs, as well as the profiles of XPS. The only difference is the molar ratio of $\mathrm{Fe} / \mathrm{Ti}$ from XPS, where the used Fe-TNTs give Fe/Ti molar ratio at 0.149 , suggesting that the partially lost ferric content should be related to the decreased activity. It is very important to note that the lost ferric content in Fe-TNTs also means the leaching of ferric species during the catalytic process; thus a new problem appears: will the leaching of ferric species contribute to the activity in homogeneous catalysis? Given that the leaching of $\mathrm{Fe}^{3+}$ is equal in three catalytic processes, the homogeneous $\left[\mathrm{Fe}^{3+}\right]$ is about $1.87 \mathrm{mM}$ in each batch. To make clear the real mechanism of Fe-TNTs, a homogeneous catalytic system is designed by using $\mathrm{Fe}^{3+}(1.87 \mathrm{mM})$ to replace Fe-TNTs $(0.1 \mathrm{~g})$, while no BC conversion can be detected after $30 \mathrm{~min}$. Even we increase $\left[\mathrm{Fe}^{3+}\right]$ to $3.36 \mathrm{mM}$; the benzylation of benzene still cannot be induced, which directly confirms that the catalytic activity indeed comes from heterogeneous catalytic sites rather than the leaching $\mathrm{Fe}^{3+}$.

In previous literatures on heterogeneous catalysis for the benzylation of benzene, the decreased catalytic activity accompanied with the leaching of active sites was a general phenomenon, because $\mathrm{HCl}$ as the main by-product could facilitate the leaching process $[2,20-22]$. Some reported catalysts seem to survive the leaching of active sites, where only several recycles were applied $[9,11,54]$. Few catalysts could keep their activities during more recycles for a long time. Once the catalytic activities of these catalysts decrease to a certain extent, they will become useless permanently for this kind of reaction. Compared with these catalysts, it is 
fortunate that the catalytic activity of Fe-TNTs can be easily recovered by treating used $\mathrm{Fe}-\mathrm{TNT}$ with $\mathrm{FeCl}_{3}$ solution again (Figure 7), although the electrostatic interaction between $\mathrm{Fe}^{3+}$ and $\left[\mathrm{TiO}_{6}\right]^{2-}$ fails to inhibit the leaching of $\mathrm{Fe}^{3+}$ completely. This unique advantage makes Fe-TNTs superior to previous catalysts, due to its possibility as a durable heterogeneous catalyst with constant activity.

\section{Conclusions}

A new kind of heterogeneous catalyst, Fe-TNTs, has been successfully prepared by treating titanate nanotubes (TNTs) with $\mathrm{Fe}^{3+}$ solution through an ion exchange process. The characterization results indicated that the process of ion exchange did not destroy the basic structure of TNTs and produced highly dispersed active sites on their surface. As a result, Fe-TNTs exhibited excellent catalytic activities in the benzylation of benzene. Even at relatively low temperature $\left(60^{\circ} \mathrm{C}\right)$, it could still perform the complete conversion of BC. More importantly, Fe-TNTs herein were universal for the benzylation of benzene and its derivatives, where the poisonous phenomenon by the adsorption of aromatic substrates in some previous catalysts was not observed. Although the steric effect more or less affected the catalytic progress, the positive contributions from electron-donating groups were still dominant, so that complete conversion of $\mathrm{BC}$ was significantly improved. During the recycling tests, the catalytic ability of Fe-TNTs could be well maintained in the initial recycle, while it became debilitated gradually with more recycles. The used catalyst was carefully characterized, and the loss of active sites in Fe-TNTs was confirmed to be primarily responsible for the decreased catalytic ability. A homogeneous system with $\mathrm{Fe}^{3+}$ equal to the leaching of active sites failed to promise any conversion of $\mathrm{BC}$, suggesting the heterogeneous nature of Fe-TNTs. Superior to other heterogeneous catalysts, the catalytic ability of used Fe-TNTs could be easily recovered by ion exchange again, which meant that Fe-TNTs were a durable heterogeneous catalyst for a series of Friedel-Crafts type benzylations. We believe that these results may open a door for the design and preparation of various heterogeneous catalysts for different organic reactions.

\section{Conflict of Interests}

The authors declare that there is no conflict of interests regarding the publication of this paper.

\section{Acknowledgments}

This work is supported by Open Project of State Key Laboratory of Urban Water Resource and Environment, HIT (QA201414), China Postdoctoral Science Foundation (2013M541394, 2014M560253, and 2014T70341), Postdoctoral Scientific Research Developmental Fund of Heilongjiang Province (LBH-Q14062), the Fundamental Research Funds for the Central Universities and PIRS of HIT (B201411), and National Natural Science Foundation of China (21446006, 21471039).

\section{References}

[1] K. Mertins, I. Iovel, J. Kischel, A. Zapf, and M. Beller, "Transition-metal-catalyzed benzylation of arenes and heteroarenes," Angewandte Chemie International Edition, vol. 44, no. 2, pp. 238-242, 2004.

[2] Y. Li, Y. Chen, L. Li et al., "A simple co-impregnation route to load highly dispersed $\mathrm{Fe}$ (III) centers into the pore structure of SBA-15 and the extraordinarily high catalytic performance," Applied Catalysis A: General, vol. 366, no. 1, pp. 57-64, 2009.

[3] V. R. Choudhary, S. K. Jana, and B. P. Kiran, "Alkylation of benzene by benzyl chloride over H-ZSM-5 zeolite with its framework Al completely or partially substituted by Fe or Ga," Catalysis Letters, vol. 59, no. 2-4, pp. 217-219, 1999.

[4] B. Coq, V. Gourves, and F. Figuéras, "Benzylation of toluene by benzyl chloride over protonic zeolites," Applied Catalysis A, General, vol. 100, no. 1, pp. 69-75, 1993.

[5] V. R. Choudhary, S. K. Jana, and B. P. Kiran, "Highly active Si-MCM-41-supported $\mathrm{Ga}_{2} \mathrm{O}_{3}$ and $\mathrm{In}_{2} \mathrm{O}_{3}$ catalysts for friedelcrafts-type benzylation and acylation reactions in the presence or absence of moisture," Journal of Catalysis, vol. 192, no. 2, pp. 257-261, 2000.

[6] S. K. Das, M. K. Bhunia, A. K. Sinha, and A. Bhaumik, "Self-assembled mesoporous zirconia and sulfated zirconia nanoparticles synthesized by triblock copolymer as template," Journal of Physical Chemistry C, vol. 113, no. 20, pp. 8918-8923, 2009.

[7] N. B. Shrigadi, A. B. Shinde, and S. D. Samant, "Study of catalytic activity of free and K10-supported iron oxyhydroxides and oxides in the Friedel-Crafts benzylation reaction using benzyl chloride/alcohol to understand their role in the catalysis by the Fe-exchanged/impregnated K10 catalysts," Applied Catalysis A: General, vol. 252, no. 1, pp. 23-35, 2003.

[8] T. Cseri, S. Békássy, F. Figueras, and S. Rizner, "Benzylation of aromatics on ion-exchanged clays," Journal of Molecular Catalysis. A, Chemical, vol. 98, no. 2, pp. 101-107, 1995.

[9] Y. Q. Jiang, K. F. Lin, Y. N. Zhang et al., "Fe-MCM-41 nanoparticles as versatile catalysts for phenol hydroxylation and for Friedel-Crafts alkylation," Applied Catalysis A: General, vol. 445-446, pp. 172-179, 2012.

[10] Y. Izumi, M. Ogawa, and K. Urabe, "Alkali metal salts and ammonium salts of Keggin-type heteropolyacids as solid acid catalysts for liquid-phase Friedel-Crafts reactions," Applied Catalysis A: General, vol. 132, no. 1, pp. 127-140, 1995.

[11] Y. C. Du, S. Liu, Y. Y. Ji et al., "Highly efficient synthesis of Fe-containing mesoporous materials by using semi-fluorinated surfactant and their high activities in Friedel-Crafts alkylations," Catalysis Today, vol. 131, no. 1-4, pp. 70-75, 2008.

[12] N. D. Cuong, N. D. Hoa, T. T. Hoa et al., "Nanoporous hematite nanoparticles: Synthesis and applications for benzylation of benzene and aromatic compounds," Journal of Alloys and Compounds, vol. 582, pp. 83-87, 2014.

[13] M. S. Hamdy and G. Mul, “TUD-1-encapsulated HY zeolite: a new hierarchical microporous/mesoporous composite with extraordinary performance in benzylation reactions," ChemCatChem, vol. 5, no. 10, pp. 3156-3163, 2013.

[14] K. Y. Leng, Y. Wang, C. M. Hou et al., "Enhancement of catalytic performance in the benzylation of benzene with benzyl alcohol over hierarchical mordenite," Journal of Catalysis, vol. 306, pp. 100-108, 2013.

[15] Z. C. Miao, H. L. Song, H. H. Zhao, L. L. Xu, and L. J. Chou, "One-pot synthesis of mesoporous $\mathrm{ZrPW}$ solid acid catalyst 
for liquid phase benzylation of anisole," Catalysis Science \& Technology, vol. 4, no. 3, pp. 838-850, 2014.

[16] V. R. Choudhary and S. K. Jana, "Benzylation of benzene by benzyl chloride over Fe-, Zn-, Ga- and In-modified ZSM-5 type zeolite catalysts," Applied Catalysis A: General, vol. 224, no. 1-2, pp. 51-62, 2002.

[17] M. Salavati-Niasari, J. Hasanalian, and H. Najafian, "Aluminasupported $\mathrm{FeCl}_{3}, \mathrm{MnCl}_{2}, \mathrm{CoCl}_{2}, \mathrm{NiCl}_{2}, \mathrm{CuCl}_{2}$, and $\mathrm{ZnCl}_{2}$ as catalysts for the benzylation of benzene by benzyl chloride," Journal of Molecular Catalysis A: Chemical, vol. 209, no. 1-2, pp. 209-214, 2004.

[18] A. Vinu, D. P. Sawant, K. Ariga et al., "Direct synthesis of well-ordered and unusually reactive FeSBA-15 mesoporous molecular sieves," Chemistry of Materials, vol. 17, no. 21, pp. 5339-5345, 2005.

[19] Y. Y. Sun, S. Walspurger, J.-P. Tessonnier, B. Louis, and J. Sommer, "Highly dispersed iron oxide nanoclusters supported on ordered mesoporous SBA-15: a very active catalyst for Friedel-Crafts alkylations," Applied Catalysis A: General, vol. 300, no. 1, pp. 1-7, 2006.

[20] Z. B. Lei, S. Y. Bai, L. Q. Dang et al., " $\mathrm{Fe}_{2} \mathrm{O}_{3} / \mathrm{SBA}-15$ catalyst synthesized by chemical vapor infiltration for Friedel-Crafts alkylation reaction," Microporous and Mesoporous Materials, vol. 123, no. 1-3, pp. 306-313, 2009.

[21] J. L. Gu, X. Dong, S. P. Elangovan et al., "Simultaneous pore enlargement and introduction of highly dispersed Fe active sites in MSNs for enhanced catalytic activity," Journal of Solid State Chemistry, vol. 186, pp. 208-216, 2012.

[22] M. E. L. Preethi, T. Sivakumar, and M. Palanichami, "Room temperature efficacious synthesis of diphenylmethane over Fe/Al-MCM-41 catalysts," Catalysis Communications, vol. 11, no. 10, pp. 876-879, 2010.

[23] K. Bachari, J. M. M. Millet, B. Benaïchouba, O. Cherifi, and F. Figueras, "Benzylation of benzene by benzyl chloride over iron mesoporous molecular sieves materials," Journal of Catalysis, vol. 221, no. 1, pp. 55-61, 2004.

[24] A. Arafat and Y. Alhamed, "Catalytic activity of mesoporous catalysts in Friedel-Crafts benzylation of benzene," Journal of Porous Materials, vol. 16, no. 5, pp. 565-572, 2009.

[25] C. Anand, G. Lawrence, A. A. Elzatahry et al., "Highly dispersed and active iron oxide nanoparticles in SBA-15 with different pore sizes for the synthesis of diphenylmethane," Science of Advanced Materials, vol. 6, no. 7, pp. 1618-1626, 2014.

[26] C. Anand, S. V. Priya, G. Lawrence et al., "Cage type mesoporous ferrosilicate catalysts with $3 \mathrm{D}$ structure for benzylation of aromatics," Catalysis Today, vol. 204, pp. 125-131, 2013.

[27] T. Kasuga, M. Hiramatsu, A. Hoson, T. Sekino, and K. Niihara, "Formation of titanium oxide nanotube," Langmuir, vol. 14, no. 12, pp. 3160-3163, 1998.

[28] X. Sun and Y. Li, "Synthesis and characterization of ionexchangeable titanate nanotubes," Chemistry: A European Journal, vol. 9, no. 10, pp. 2229-2238, 2003.

[29] Z. S. Hong, X. Z. Zheng, X. K. Ding, L. L. Jiang, M. D. Wei, and K. M. Wei, "Complex spinel titanate nanowires for a high rate lithium-ion battery," Energy and Environmental Science, vol. 4, no. 5, pp. 1886-1891, 2011.

[30] D. V. Bavykin, A. A. Lapkin, P. K. Plucinski, J. M. Friedrich, and F. C. Walsh, "Reversible storage of molecular hydrogen by sorption into multilayered $\mathrm{TiO}_{2}$ nanotubes," The Journal of Physical Chemistry B, vol. 109, no. 41, pp. 19422-19427, 2005.
[31] H.-H. Ou, C.-H. Liao, Y.-H. Liou, J.-H. Hong, and S.L. Lo, "Photocatalytic oxidation of aqueous ammonia over microwave-induced titanate nanotubes," Environmental Science \& Technology, vol. 42, no. 12, pp. 4507-4512, 2008.

[32] T. Wang, W. Liu, N. Xu, and J. Ni, "Adsorption and desorption of Cd(II) onto titanate nanotubes and efficient regeneration of tubular structures," Journal of Hazardous Materials, vol. 250251, pp. 379-386, 2013.

[33] D. V. Bavykin, A. A. Lapkin, P. K. Plucinski, L. TorrenteMurciano, J. M. Friedrich, and F. C. Walsh, "Deposition of Pt, $\mathrm{Pd}, \mathrm{Ru}$ and $\mathrm{Au}$ on the surfaces of titanate nanotubes," Topics in Catalysis, vol. 39, no. 3-4, pp. 151-160, 2006.

[34] M. Kitano, E. Wada, K. Nakajima et al., "Protonated titanate nanotubes with Lewis and Brønsted acidity: relationship between nanotube structure and catalytic activity," Chemistry of Materials, vol. 25, no. 3, pp. 385-393, 2013.

[35] E. Wada, M. Kitano, K. Nakajima, and M. Hara, "Effect of preparation conditions on the structural and acid catalytic properties of protonated titanate nanotubes," Journal of Materials Chemistry A, vol. 1, no. 41, pp. 12768-12774, 2013.

[36] Q. Chen, G. H. Du, S. Zhang, and L. M. Peng, "The structure of trititanate nanotubes," Acta Crystallographica Section B: Structural Science, vol. 58, no. 4, pp. 587-593, 2002.

[37] W. Liu, T. Wang, A. G. L. Borthwick et al., "Adsorption of $\mathrm{Pb}^{2+}$, $\mathrm{Cd}^{2+}, \mathrm{Cu}^{2+}$ and $\mathrm{Cr}^{3+}$ onto titanate nanotubes: competition and effect of inorganic ions," Science of the Total Environment, vol. 456-457, pp. 171-180, 2013.

[38] C.-K. Lee, K.-S. Lin, C.-F. Wu, M.-D. Lyu, and C.-C. Lo, "Effects of synthesis temperature on the microstructures and basic dyes adsorption of titanate nanotubes," Journal of Hazardous Materials, vol. 150, no. 3, pp. 494-503, 2008.

[39] X. K. Li and Y. S. Zhong, "Ion-exchangeable titanate nanotubes with visible light responsive photocatalytic activities for dyes degradation," Journal of Nanoscience and Nanotechnology, vol. 14, no. 9, pp. 7151-7156, 2014.

[40] Y. X. Tang, D. G. Gong, Y. K. Lai et al., "Hierarchical layered titanate microspherulite: formation by electrochemical spark discharge spallation and application in aqueous pollutant treatment," Journal of Materials Chemistry, vol. 20, no. 45, pp. 1016910178, 2010.

[41] M. Qamar, S. J. Kim, and A. K. Ganguli, “ $\mathrm{TiO}_{2}$-based nanotubes modified with nickel: synthesis, properties, and improved photocatalytic activity," Nanotechnology, vol. 20, no. 45, Article ID 455703, 2009.

[42] B. C. Viana, O. P. Ferreira, A. G. Souza Filho et al., "Decorating titanate nanotubes with $\mathrm{CeO}_{2}$ nanoparticles," Journal of Physical Chemistry C, vol. 113, no. 47, pp. 20234-20239, 2009.

[43] S.-T. Myung, N. Takahashi, S. Komaba et al., "Nanostructured $\mathrm{TiO}_{2}$ and its application in lithium-ion storage," Advanced Functional Materials, vol. 21, no. 17, pp. 3231-3241, 2011.

[44] M. Kim, S.-H. Hwang, S. K. Lim, and S. Kim, "Effects of ion exchange and calcinations on the structure and photocatalytic activity of hydrothermally prepared titanate nanotubes," Crystal Research and Technology, vol. 47, no. 11, pp. 1190-1194, 2012.

[45] L. Shi, L. X. Cao, W. Liu, G. Su, R. J. Gao, and Y. L. Zhao, "A study on partially protonated titanate nanotubes: enhanced thermal stability and improved photocatalytic activity," Ceramics International, vol. 40, no. 3, pp. 4717-4723, 2014.

[46] L. Guo, Z. Q. Zhou, and H. M. Yuan, "Hydrothermal synthesis and magnetic properties of $\mathrm{Fe}^{3+}$-doped multiferroic hexagonal rare-earth manganates," Journal of Alloys and Compounds, vol. 616, pp. 454-460, 2014. 
[47] Y. C. Du, Y. Yang, S. Liu, N. Xiao, Y. L. Zhang, and F.-S. Xiao, "Mesoporous aluminophosphates and Fe-aluminophosphates with highly thermal stability and large surface area templated from semi-fluorinated surfactant," Microporous and Mesoporous Materials, vol. 114, no. 1-3, pp. 250-256, 2008.

[48] V. R. Choudhary, R. Jha, and V. S. Narkhede, "In-Mghydrotalcite anionic clay as catalyst or catalyst precursor for Friedel-Crafts type benzylation reactions," Journal of Molecular Catalysis A: Chemical, vol. 239, no. 1-2, pp. 76-81, 2005.

[49] V. R. Choudhary and R. Jha, " $\mathrm{GaCl}_{x}$ - or $\mathrm{GaAlCl}_{x}$-grafted SiMCM-41: highly active and moisture insensitive/stable catalyst for the acylation and benzylation of benzene, naphthalene and substituted benzenes," Applied Catalysis A: General, vol. 333, no. 1, pp. 42-48, 2007.

[50] N. He, S. Bao, and Q. Xu, "Fe-containing mesoporous molecular sieves materials: very active Friedel-Crafts alkylation catalysts," Applied Catalysis A: General, vol. 169, no. 1, pp. 29-36, 1998.

[51] K. Y. Leng, S. N. Sun, B. T. Wang, L. Sun, W. Xu, and Y. Y. Sun, "Benzylation of benzene with benzyl chloride on ironcontaining mesoporous mordenite," Catalysis Communications, vol. 28, pp. 64-68, 2012.

[52] V. R. Choudhary, S. K. Jana, N. S. Patil, and S. K. Bhargava, "Friedel-Crafts type benzylation and benzoylation of aromatic compounds over $\mathrm{H}$ beta zeolite modified by oxides or chlorides of gallium and indium," Microporous and Mesoporous Materials, vol. 57, no. 1, pp. 21-35, 2003.

[53] Y. C. Du, S. Liu, Y. L. Zhang, F. Nawaz, Y. Y. Ji, and F. S. Xiao, "Urea-assisted synthesis of hydrothermally stable ZrSBA-15 and catalytic properties over their sulfated samples," Microporous and Mesoporous Materials, vol. 121, no. 1-3, pp. 185193, 2009.

[54] K. Bachari and O. Cherifi, "Study of the benzylation of benzene and other aromatics by benzyl chloride over transition metal chloride supported mesoporous SBA-15 catalysts," Journal of Molecular Catalysis A: Chemical, vol. 260, no. 1-2, pp. 19-23, 2006. 

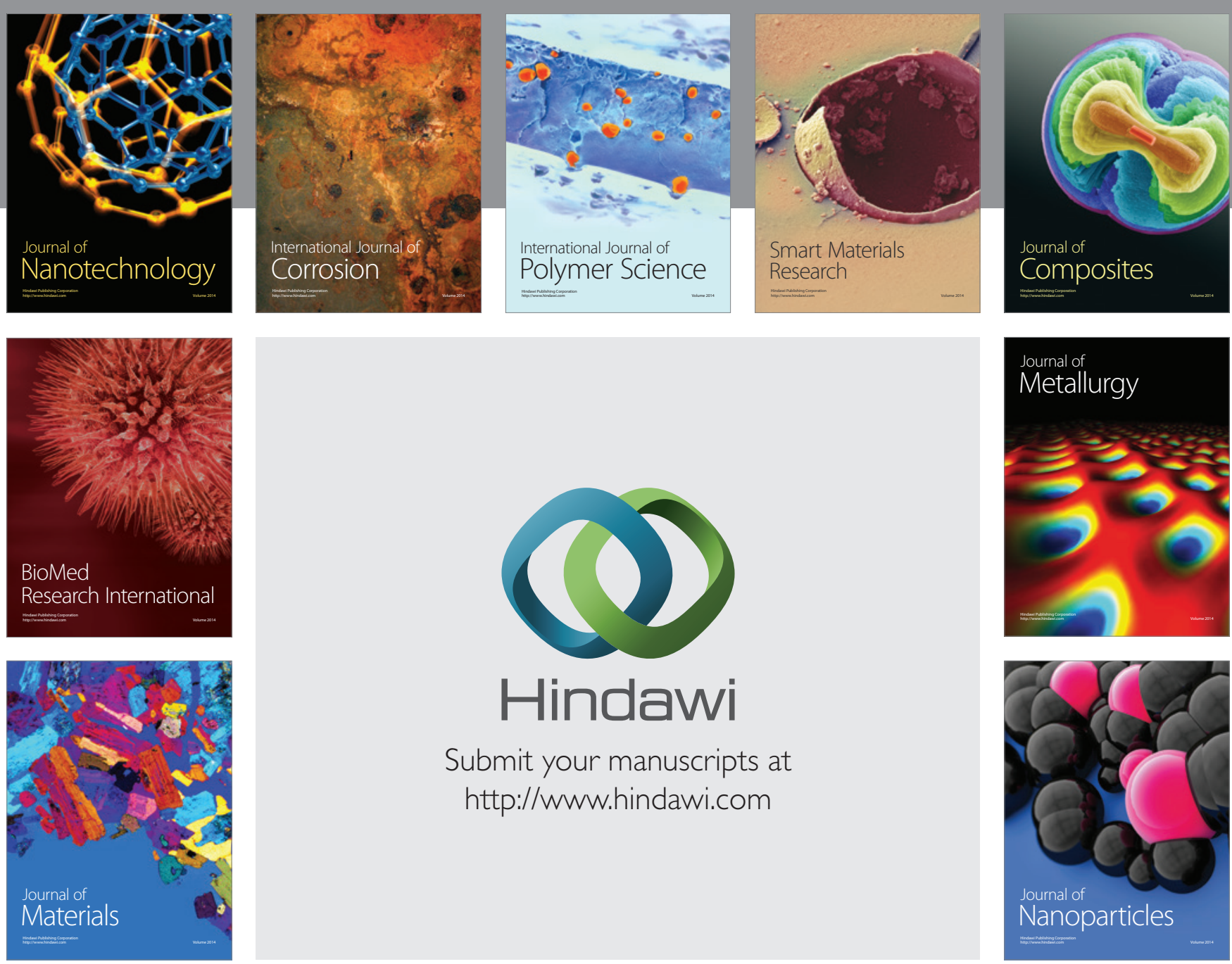

Submit your manuscripts at http://www.hindawi.com
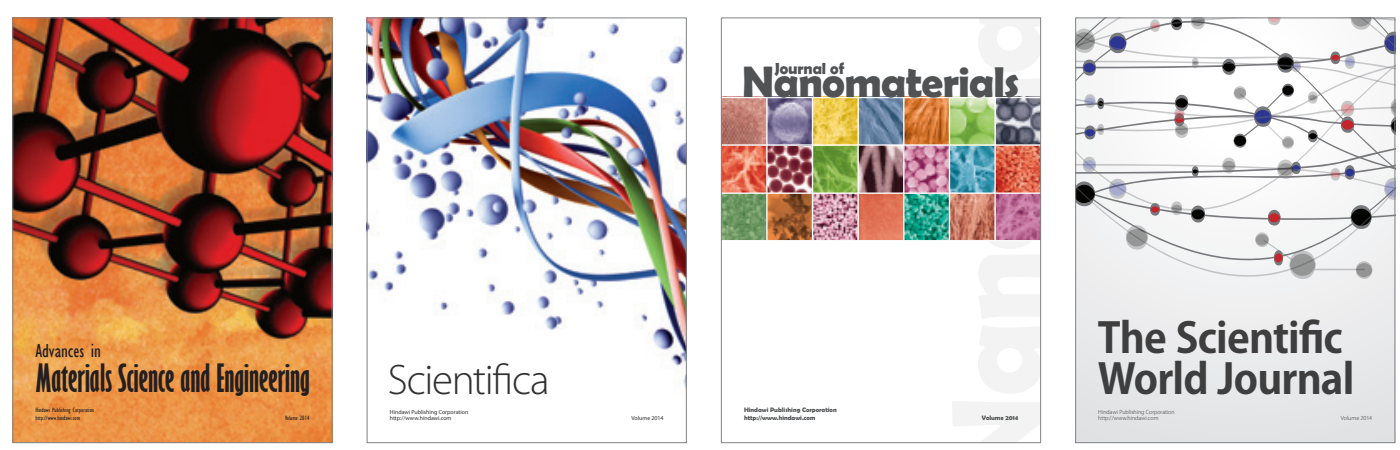

\section{The Scientific World Journal}
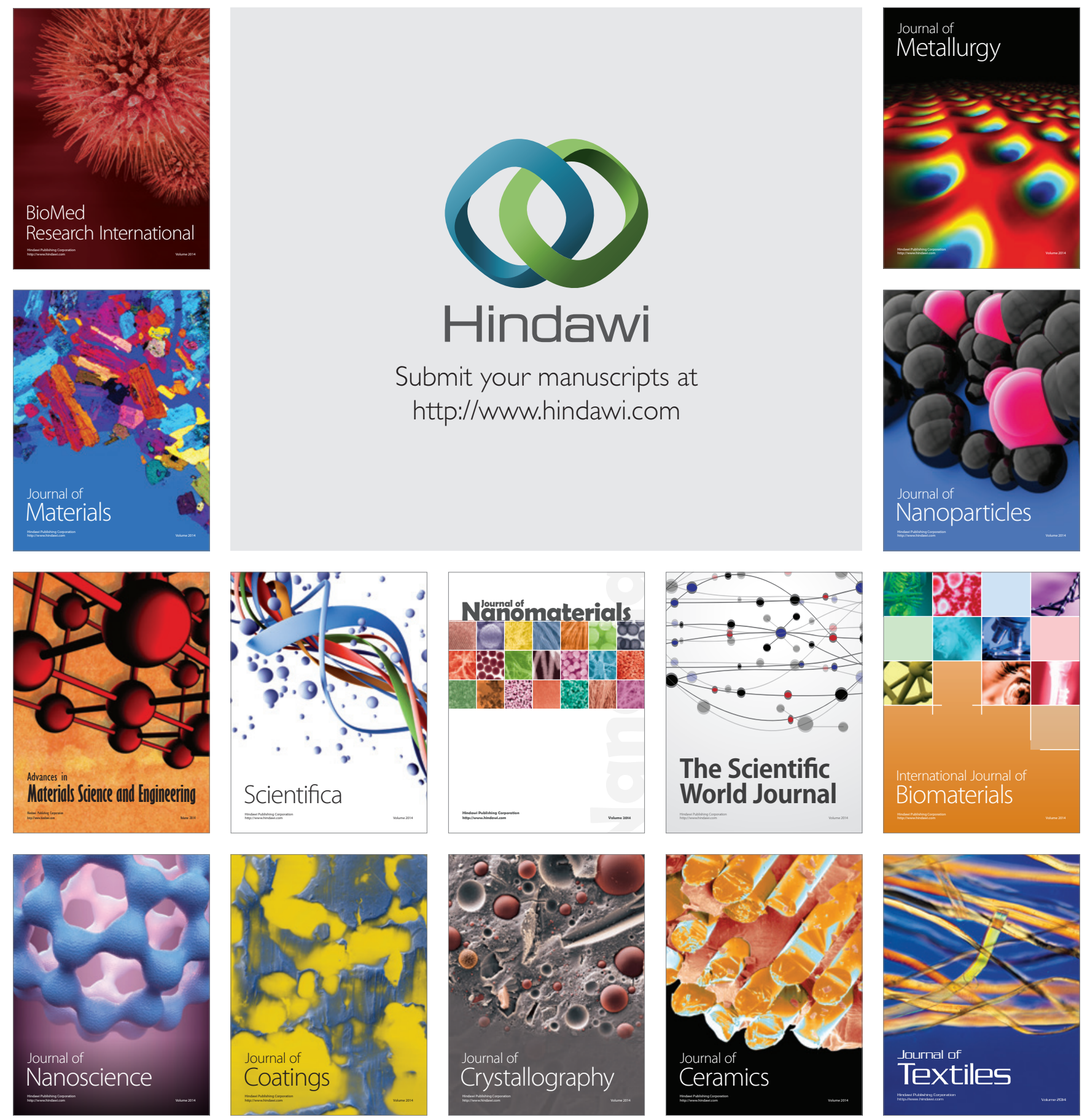